\title{
A BUSCA DA INTERAÇÃO TEORIA E PRÁTICA NO SISTEMA DE INFORMAÇÃO EM ENFERMAGEM - ENFOQUE NA TEORIA FUNDAMENTADA NOS DADOS ${ }^{1}$
}

Sérgio Ribeiro dos Santos ${ }^{2}$ Maria Miriam Lima da Nóbrega²

Santos SR, Nóbrega MML. A busca da interação teoria e prática no sistema de informação em enfermagem - enfoque na teoria fundamentada nos dados. Rev Latino-am Enfermagem 2004 maio-junho; 12(3):460-8.

Estudo qualitativo buscou compreender, por meio do discurso dos enfermeiros, a relação teoria-prática em enfermagem e suas implicações para o desenvolvimento de sistemas de informação. A teoria fundamentada nos dados foi utilizada como referencial metodológico. A população foi constituída por enfermeiros que atuam na clínica médica de um hospital-escola. A análise dos dados resultou na categoria central: a busca da interação teoria-prática no sistema de informação em enfermagem. Tal processo foi constituído pela integração entre categorias no modelo do paradigma de Strauss e Corbin em dois fenômenos: a tentativa de aplicar os modelos formais na prática de enfermagem e a visão da lacuna teoria-prática no sistema de informação em enfermagem.

DESCRITORES: sistemas de informação; enfermagem; métodos

\section{THE SEARCH FOR THEORY-PRACTICE INTERACTION IN THE NURSING INFORMATION SYSTEM - APPROACH FROM GROUNDED THEORY}

This qualitative study aimed to understand, through nursing discourse, the relation between theory and practice in nursing and its implications for the development of information systems. Grounded theory was used as a methodological reference framework. The study population consisted of nurses who work at the clinic of a school hospital. Data analysis resulted in the main category: The search for theory-practice interaction in the nursing information system. This process was formed by the integration among categories, based on Strauss and Corbin's paradigm as a model with two phenomena: the attempt to apply the formal models in nursing practice and the perspective of the theory-practice gap in the nursing information system.

DESCRIPTORS: information systems; nursing; methods

\section{LA BÚSQUEDA DE LA INTERACCIÓN TEORÍA-PRÁCTICA EN EL SISTEMA DE INFORMACIÓN EN ENFERMARÍA - ENFOQUE EN LA TEORÍA FUNDAMENTADA EN LOS DATOS}

La finalidad de este estudio cualitativo fue comprender, mediante el discurso de los enfermeros, la relación teoríapráctica en enfermería y sus implicaciones para el desarrollo de sistemas de información. La teoría fundamentada en los datos fue utilizada como referencial metodológico. La población fue constituída por enfermeros que actúan en la clínica médica de un hospital escuela. El análisis de los datos resultó en la categoría central: La búsqueda de la interacción teoría-práctica en el sistema de información en enfermería. Tal proceso fue constituido por la integración entre categorías en el modelo del paradigma de Strauss y Corbin en dos fenómenos: la tentativa de aplicar los modelos formales en la práctica de la enfermería y la visión de la laguna teoría-práctica en el sistema de información en enfermería.

DESCRIPTORES: sistemas de información; enfermería; métodos

\footnotetext{
${ }^{1}$ Trabalho extraído da Tese de Doutorado desenvolvido e aprovado no programa de Pós-Graduação em Ciências da Saúde do Centro de Ciências da Saúde da Universidade Federal da Paraíba; ${ }^{2}$ Enfermeiro, Professor Doutor, e-mail: s.r.santos@uol.com.br. Universidade Federal da Paraíba. Agradecemos as orientações do Prof. Dr. José Rodrigues Filho
} 
Durante a nossa trajetória acadêmica, sempre tivemos interesse pela área de Sistemas de Informação. Assim, na tentativa de aprofundarmos os conhecimentos na área de tecnologia da informação, passamos a atuar junto aos usuários de sistemas computadorizados. Em nossas observações, constatamos que a informação é fundamental para a assistência e gerenciamento do serviço de enfermagem, mas isso requer interpretação e integração de complexas informações clínicas, que vão apoiar e ajudar o enfermeiro na tomada de decisão, especialmente, no tocante à resolução e minimização dos problemas de saúde do cliente.

Diante disso, nasceu o propósito de compreender a relação entre teoria e prática em sistemas de informação em enfermagem, com base na vivência dos enfermeiros, a fim de que pudéssemos dispor de informações que ajudassem a subsidiar o desenvolvimento de sistemas de informação e proporcionar segurança na prestação da assistência ao paciente. Mas o grande desafio é saber de que informação o enfermeiro necessita para gerenciar com qualidade os cuidados de enfermagem. Percebemos que o volume de informações sobre o paciente cresce nos protocolos de tratamento, e o registro manual no prontuário torna-se cada vez mais ineficaz para garantir armazenamento e gerenciamento dessas informações ${ }^{(1)}$.

Para mudar essa situação, é fundamental identificar a informação necessária que satisfaça aos objetivos sociais e organizacionais. Isso implica compreender os aspectos teórico-práticos da enfermagem, os quais são indispensáveis para o desenvolvimento de sistemas. Por ser inovadora, essa abordagem não é vista nos hospitais como prioridade para efeito de automação do serviço de enfermagem. Assim, mediante tais considerações, a questão emergente que norteou este estudo foi a seguinte:

- A compreensão da relação entre teoria e prática no trabalho da enfermagem permitirá o desenvolvimento de sistemas de informação mais adequado à realidade vivenciada pelos enfermeiros?

Partindo desse questionamento, este estudo se propôs alcançar os seguintes objetivos:

a) compreender, pelo discurso dos enfermeiros, a relação entre teoria e prática em enfermagem e suas implicações para o desenvolvimento de sistemas de informação; experiência dos enfermeiros.

\section{REFERENCIAL TEÓRICO}

Analisando o contexto deste estudo, optamos pelo paradigma interpretativo, de modo a tornar possível, não só compreender o quadro referencial dentro do qual os enfermeiros interpretam as suas percepções, mas também apreender as várias dimensões de sua prática em termos de sistemas de informação. Por essa perspectiva, utilizamos o interacionismo simbólico, dentro do paradigma interpretativo, permitindo que a pesquisa cumprisse 0 objetivo de investigar o sentido que os atores sociais dão aos objetos, pessoas e símbolos com os quais constroem o seu mundo social.

O interacionismo simbólico é uma das formas de se interpretarem as percepções das pessoas, o significado e o sentido que elas dão às coisas e como esses relatos se relacionam com as experiências ${ }^{(2)}$. É uma metodologia empírica que usa alguns procedimentos como: estudos de caso, entrevistas, observação participante, história de vida, conversações, análise de documentos, cartas, diários, dentre outros. Portanto, é sob a ótica do interacionismo simbólico e com a aplicação do método da teoria fundamentada nos dados que serão delineadas algumas considerações.

O interacionismo simbólico tem sua utilidade, que é originar novas teorias, cuja exigência é a manutenção das conjeturas abordadas, proporcionando uma visão do homem com sua interação no processo de definir, responder, interagir e raciocinar ${ }^{(3)}$. A seguir, serão descritos os conceitos centrais que servem de base à compreensão das idéias a respeito do interacionismo simbólico.

O símbolo é o ponto central do interacionismo simbólico, pois, sem ele, os seres humanos não podem interagir uns com os outros. Símbolos são objetos sociais usados pelo ator para representação e comunicação; self (o ego/a própria pessoa) significa que a pessoa pode ser objeto de sua própria ação, ou seja, objeto de si própria. Para os interacionistas, o selfé um objeto social por meio do qual o indivíduo age; a mente é um processo que se manifesta sempre que o indivíduo interage consigo próprio, usando símbolos significantes. Essa significância ou sentido é também social em sua origem. Da mesma forma, a mente também é social, tanto em sua origem como em 
sua função, porque ela surge do processo social de comunicação $^{(4-5)}$.

Esses conceitos levam ao entendimento do que seja interação social, ou seja, as pessoas são vistas como atores que se relacionam, comunicam-se e interpretam um ao outro. A interação social é construída a partir da ação social. A ação é formada à luz da situação na qual ela acontece. As pessoas agem de acordo com a forma de sua interpretação da situação. Assim, a interação simbólica envolve interpretação e definição e ocorre entre as pessoas envolvidas ${ }^{(4)}$.

A sociedade é toda atividade grupal que se baseia no comportamento cooperativo. O comportamento humano envolve uma resposta às intenções dos outros. Essas intenções são transmitidas por meio de gestos que se tornam simbólicos e passíveis de serem interpretados ${ }^{(6)}$.

Dessa forma, o interacionismo é uma ferramenta teórica que possibilita a compreensão do fenômeno de uma maneira mais ampla, além de revelar e apontar o significado que a relação teoria e prática em enfermagem tem para o enfermeiro e o que representa para o desenvolvimento de sistemas de informação. Possibilita, ainda, compreender se esse significado é decorrente ou resultante da interação que o enfermeiro faz com os elementos envolvidos no processo assistencial. Procura saber se esses elementos são significativos, toda vez que interagem no seu ambiente de trabalho e como ele utiliza o processo interpretativo ao agir mutuamente, com os objetos mais significativos de sua prática.

\section{METODOLOGIA}

Para melhor compreensão do fenômeno investigado, optamos pelo enfoque do método qualitativo, na tentativa de descobrir e entender o que há por trás do sistema de informação em enfermagem, porque acreditamos que o método quantitativo não é capaz de apresentar respostas, fruto de uma profunda reflexão da experiência vivenciada na prática.

Após refletir sobre os vários métodos de pesquisa, chegamos à conclusão de que a abordagem da teoria fundamentada nos dados mostrou-se mais apropriada para este estudo, porque procura investigar os processos nos quais estão ocorrendo os fenômenos. Além disso, busca uma fundamentação detalhada para, a partir daí, realizar a análise sistemática dos dados e fazer comparações destes, até que surja a teoria ${ }^{(7)}$.

Este estudo foi realizado num hospital escola da cidade de João Pessoa - Paraíba. Por se tratar de um centro de referência na formação de profissionais de enfermagem no Estado, essa instituição possui em desenvolvimento, na Unidade de Clínica Médica, o processo de sistematização da assistência de enfermagem.

Os participantes da pesquisa foram enfermeiros assistenciais. A participação desses profissionais na pesquisa dependeu da concordância e disponibilidade em contribuir com o estudo. Antes de iniciar o processo de coleta dos dados, o projeto de pesquisa foi submetido ao Comitê de Ética em Pesquisa - CEP, da Universidade Federal da Paraíba. Durante o transcorrer desse processo, tivemos sempre a preocupação em zelar pelas observâncias éticas, preconizadas para a pesquisa envolvendo seres humanos, de acordo com o Item IV, da Resolução no 196/96, do Conselho Nacional de Saúde ${ }^{(8)}$. De forma que, a cada entrevista realizada, o participante assinava o termo de consentimento livre e esclarecido, sendo informado sobre os objetivos e procedimentos que seriam utilizadas na pesquisa.

A população de enfermeiros da clínica médica era constituída por vinte profissionais. Na amostragem teórica, procuramos coletar dados que pudessem subsidiar a teoria, de forma que, ao coletar, codificar e analisar os dados, tivemos condições de decidir se havia ou não a necessidade de coletar mais dados, até alcançar a saturação teórica, que ocorre quando nenhum dado adicional for capaz de acrescentar algo novo. A saturação da amostragem foi alcançada com doze entrevistas.

As técnicas de coleta de dados utilizadas foram a observação participante e a entrevista. A fase de observação permitiu maior interação com o pessoal de enfermagem durante as reuniões nas salas de aula do hospital. As entrevistas e as observações que foram registradas permitiram compreender o significado da experiência dos enfermeiros em relação à teoria e à prática do sistema de informação, no qual procuramos recompor o processo como um todo.

O início das entrevistas aconteceu após algumas semanas de convivência com os enfermeiros no ambiente hospitalar. Aentrevista foi realizada no decorrer do processo, como estratégia preferencial para a compreensão dos dados obtidos. Dentre as diferentes formas de entrevista, 
escolhemos a entrevista semi-estruturada que parte de questões norteadoras que interessam à pesquisa ${ }^{(9)}$.

A cada entrevista concluída, fazíamos a transcrição e revisão minuciosa do texto com a audição da fita cassete, comparando a fala com o texto. A partir daí, demos início ao processo de recorte ou identificação das unidades de análise dos dados. Um a um, eram codificados, separados e impressos num quadro, contendo, na margem esquerda, os dados identificados e, na margem direita, os códigos. Em seguida, passamos ao processo de reflexão sobre cada código atribuído aos dados identificados, separando-os por afinidade, semelhança, ou, ainda, se apresentassem alguma relação ou complementação de idéias ou expressões.

Para compreender o significado dos dados, procedemos à análise, codificando-os, categorizando-os e identificando a categoria central. A codificação foi feita manualmente, e os códigos foram anotados na margem direita da página. Essa etapa é denominada de codificação aberta $^{(10)}$. Na etapa seguinte, atribuímos um conceito para cada agrupamento de dados realizados, código por código, que tinha algumas semelhanças entre si ou características distintas. Os dados categorizados receberam a denominação de categorias.

Dando prosseguimento à análise dos dados, passamos à etapa designada de codificação axial ${ }^{(10)}$, isso significa que os dados são agrupados em novas formas estabelecendo uma conexão entre as categorias, buscando expandir e compactar a teoria emergente. Essas operações são denominadas de conexões teóricas. As conexões são estabelecidas entre uma categoria e suas subcategorias, em termos das condições causais, contexto, condições intervenientes, estratégias e conseqüências $^{(11)}$.

$\mathrm{Na}$ etapa seguinte do processo analítico, as categorias foram trabalhadas em profundidade $\mathrm{e}$ consistência. Esse refinamento é chamado de codificação seletiva, que consiste num processo de integração entre as categorias e subcategorias definidas, após a descrição analítica do relato, até descobrir a categoria central que deve estar presente na maioria dos relatos e deve ser ampla e abstrata, para incluir e expressar todas as outras. A categoria central é o cimento condutor que coloca e mantém juntos todos os componentes da teoria, ou seja, a categoria central torna explícita a experiência vivenciada pelos enfermeiros na construção do modelo conceitual ${ }^{(10)}$.

\section{RESULTADOS E DISCUSSÃO}

A apresentação dos resultados deste estudo tem início com uma compreensão das experiências dos enfermeiros, a partir da identificação de dois fenômenos: a tentativa de articular os modelos formais com a prática de enfermagem, para desenvolver sistemas de informação - Figura 1; e a visão da lacuna entre teoria e prática no sistema de informação em enfermagem - Figura 2. A relação entre as categorias permitiu o estabelecimento da integração e compreensão dos fenômenos, tarefa que foi facilitada com a aplicação do modelo de paradigma de Strauss e Corbin (condições causais, contexto, condições intervenientes, estratégias e conseqüências) ${ }^{(10)}$ e a interpretação à luz do Interacionismo Simbólico.

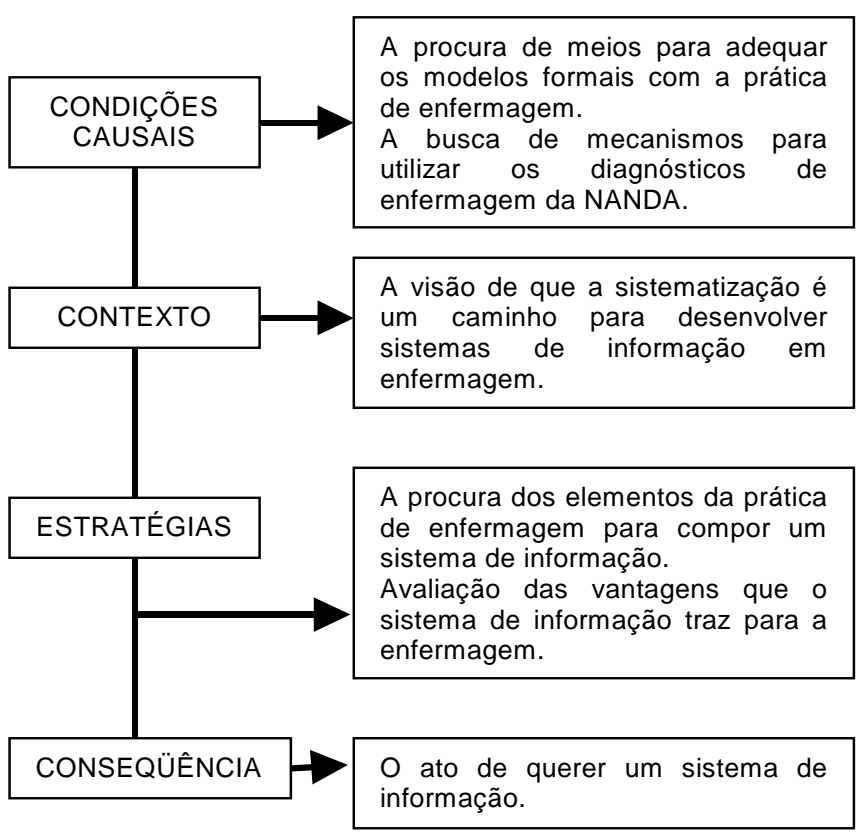

Figura 1 - A tentativa de articular os modelos formais com a prática de enfermagem para desenvolver sistemas de informação-FENÔMENO 1

A Figura 1 mostra a situação da prática do enfermeiro assistencial na tentativa de desenvolver cuidados de enfermagem respaldados numa base teóricocientífica, retratada pelos modelos formais aqui denominados sistematização da assistência de enfermagem. Até agora, os enfermeiros não têm um vocabulário padronizado, uma taxonomia e um sistema de classificação que possam servir de referência para aplicar na prática e desenvolver sistemas de informação que representem os elementos da sua prática em todas as diferentes situações vivenciadas por eles. 
Destaque das condições causais para o fenômeno 1

Esse grupo de categorias revela as causas que desencadeiam o fenômeno em estudo. São consideradas causais porque os enfermeiros estão envolvidos no processo de sistematização da assistência de enfermagem em que, efetivamente, estudam os modelos formais fundamentados nos sistemas de classificação e nos diagnósticos de enfermagem da NANDA (North American Nursing Diagnosis Association). Com isso, não só apóiam as fases do processo de enfermagem (histórico, diagnóstico, intervenção, implementação e avaliação), como também contribuem para o registro computadorizado em enfermagem.

Mas, ao tentarem articular os modelos formais com a prática de enfermagem, os enfermeiros também fazem uso dos diagnósticos de enfermagem da NANDA, na tentativa de utilizá-los na prática. Portanto, a categoria, a busca de mecanismos para utilizar os diagnósticos de enfermagem da NANDA é uma conseqüência da categoria: a procura de meios para adequar os modelos formais com a prática de enfermagem.

Destaque do contexto para o fenômeno 1

A categoria relacionada ao contexto é: a visão de que a sistematização é um caminho para desenvolver sistemas de informação em enfermagem. Essa categoria explica o fato de os enfermeiros quererem aplicar os modelos formais na prática de enfermagem, a partir de uma metodologia de trabalho que sistematize suas ações e organize o trabalho, de forma que produzam resultados que possam ser mensurados. Os enfermeiros vêem a sistematização dos cuidados de enfermagem como uma forma de aprofundar os conhecimentos e melhorar a qualidade da assistência e do registro das informações de enfermagem.

Estratégias de ação para o fenômeno 1

Diante da possibilidade de desenvolver um sistema de informação que revele o que a enfermagem produz no dia-a-dia, essa percepção provocou as seguintes estratégias de ação: a procura dos elementos da prática de enfermagem para compor um sistema de informação; avaliação das vantagens que o sistema de informação traz para a enfermagem. Acreditamos que a experiência do profissional de enfermagem venha resgatar 0 conhecimento tácito inerente à prática clínica do enfermeiro. Assim, os elementos da prática de enfermagem existentes na sistematização são fundamentais para desenvolver sistemas de informação.

Conseqüências para o fenômeno 1

A conseqüência resultante das expectativas dos enfermeiros envolve a seguinte categoria: $o$ ato de querer um sistema de informação. Um dos maiores objetivos da informática em enfermagem é implantar um sistema de informação clínica que inclua as necessidades da enfermagem para processamento de informações que apóiem a sua prática, inclusive as peculiaridades contingenciais e os padrões de sistemas ${ }^{(12-13)}$.

Como se sabe, um sistema de informação consiste num conjunto de elementos formado por pessoas, informações, processos, hardware e software, que, trabalhando juntos, complementam-se para desenvolver funções específicas ${ }^{(14)}$. Mas, para que esses benefícios aconteçam, é indispensável a participação ativa dos enfermeiros no desenvolvimento do sistema, a fim de potencializar o crescimento e a autodeterminação indispensáveis para o questionamento e a transformação do conhecimento tácito em conhecimento explícito automatizado.

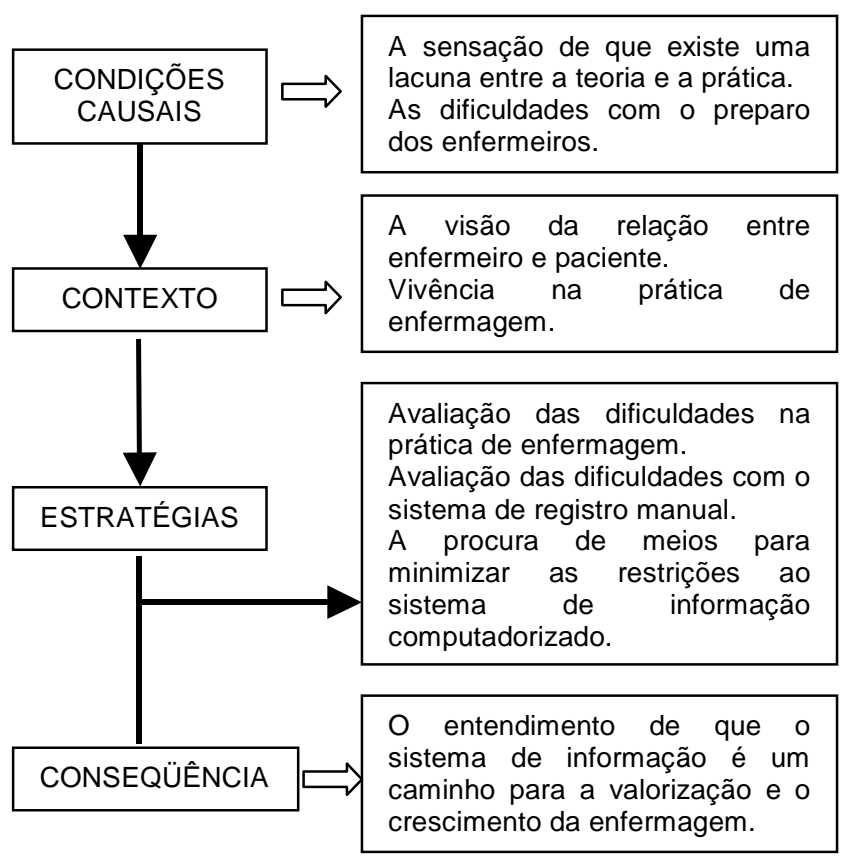

Figura 2 - A visão da lacuna entre teoria e prática no sistema de informação em enfermagem - FENÔMENO 2 
A Figura 2 tenta explicar as influências que a lacuna existente entre a teoria e a prática de enfermagem provoca no desenvolvimento de sistemas de informação, assim como no preparo dos enfermeiros. Não há dúvida de que essa situação afeta o desempenho da prática de enfermagem, que requer uma conexão integral entre a teoria e a prática, como medidas inseparáveis. Em tese, a relação teoria-prática pode ser fortalecida pelo uso de uma abordagem interpretativa e pela visão de que a realidade é sociável.

Destaque das condições causais para o fenômeno 2

As categorias: a sensação de que existe uma lacuna entre a teoria e a prática; e as dificuldades com o preparo dos enfermeiros mostram as causas que desencadeiam o fenômeno 2. São consideradas causais, porque nascem da preocupação dos enfermeiros ao perceberem que existe uma lacuna entre a teoria e a prática. Essa lacuna pode dificultar não só o desempenho clínico, como também o desenvolvimento de sistemas de informação e o preparo dos enfermeiros.

A lacuna teoria-prática em enfermagem não existe como resultado da falha dos enfermeiros assistenciais para ler e implementar os estudos realizados. O problema é que a maioria dos estudos em enfermagem é executado dentro de uma estrutura teórica inadequada para a prática de enfermagem atual ${ }^{(15)}$. Na realidade, o modelo acadêmico que prevalece no preparo dos enfermeiros é o técnico-racional, que descreve uma perspectiva científica da enfermagem como um conhecimento hierárquico, teórico e de status acadêmico. No entanto, acreditamos que somente por uma abordagem crítica é que se pode dimensionar a ciência aplicada, o conhecimento e a prática de enfermagem, que são essenciais no preparo dos enfermeiros.

Destaque do contexto para o fenômeno 2

As categorias indicativas são: a visão da relação entre enfermeiro e paciente; e vivência na prática de enfermagem. Essas categorias destacam o contexto em que a lacuna teoria-prática se insere, influenciando no desempenho e no desenvolvimento de sistemas de informação.

A categoria a visão da relação entre enfermeiro e paciente está orientada para uma visão da enfermagem holística. Refere-se à prática de enfermagem em que os enfermeiros desempenham pessoalmente ações que proporcionem benefícios, mantenham a vida, a saúde e o bem-estar do paciente. Nessa perspectiva, a qualidade da assistência não depende apenas da execução de ações e técnicas bem planejadas, mas também de um sentimento de empatia.

A percepção dos enfermeiros reveladas na categoria vivência na prática de enfermagem é de que a enfermagem caracteriza-se como uma profissão assistencial pautada no paradigma funcionalista, que traz de maneira contundente o seu lado negativo, quando atribui grande ênfase ao ato de cuidar do paciente como se fosse um ritual de ações com inúmeros procedimentos tarefeiros e mecanicistas. Nesse modelo, o que importa é somente o volume de trabalho realizado, geralmente fragmentado, em que o auxiliar de enfermagem é responsável pelas tarefas (medicação, controle de sinais vitais, diurese, etc.), e os enfermeiros, pela parte administrativa.

Estratégias de ação para o fenômeno 2

Os problemas decorrentes da lacuna teoria e prática e as dificuldades no preparo dos enfermeiros, que caracterizam a prática de enfermagem, foram revelados pelos enfermeiros, propiciando as seguintes estratégias de ação: avaliação das dificuldades na prática de enfermagem, avaliação das dificuldades com o sistema de registro manual e a procura de meios para minimizar as restrições ao sistema de informação computadorizado.

A prática de enfermagem na clínica médica apresenta muitas dificuldades que têm preocupado os enfermeiros, por causa do comprometimento com a qualidade da assistência prestada ao paciente e ainda com a satisfação profissional. Os enfermeiros externaram suas inquietações, pelos seguintes depoimentos:

[...] a gente vê uma insatisfação muito grande por parte dos enfermeiros e auxiliares de enfermagem, insatisfação no trabalho.

[...] a gente tem dificuldade, mas estamos lutando para buscar mais conhecimento.

[...] a enfermagem não tem muito valor, porque os próprios profissionais não conquistam.

Para os enfermeiros, essas dificuldades transcendem a capacidade de atuação, embora estejam dispostos a lutar para superá-las. Também os enfermeiros têm se deparado com a ausência de supervisão para 
acompanhar o desenvolvimento das atividades assistenciais de enfermagem.

A categoria: avaliação das dificuldades com o sistema de registro manual trata de mais uma dificuldade enfrentada pelos enfermeiros. Por seus relatos, os enfermeiros apontam falhas no mecanismo de armazenamento de dados. Apesar de desenvolverem o método da sistematização da assistência, os registros não sofreram qualquer mudança que viesse a agilizar a recuperação dos dados, organizá-los e disponibilizá-los para o livre acesso dos profissionais de saúde. Não obstante as dificuldades percebidas pelos enfermeiros, eles reconhecem a importância do registro para a prática de enfermagem:

[...] o que a gente precisa realmente é primar mais pelos registros, documentar e também aprofundar mais essas questões.

A categoria: a procura de meios para minimizar as restrições ao sistema de informação computadorizado gera, nos enfermeiros, a percepção de que seus conhecimentos em tecnologia e sistemas de informação são superficiais e não thes dão segurança para o desenvolvimento de registros em enfermagem inerentes à sua função. Mediante essa percepção, os enfermeiros sentem a necessidade de adquirir conhecimentos que lhes proporcionem o entendimento das necessidades de informação para usar a tecnologia adequada e habilidade para comunicar esse conhecimento para outros, por meio do uso de um sistema de informação computadorizado.

\section{Conseqüências para o fenômeno 2}

Como conseqüência da percepção dos enfermeiros de que existe uma lacuna entre a teoria e a prática de enfermagem resultou a categoria: 0 entendimento de que o sistema de informação é um caminho para a valorização e o crescimento da enfermagem. Os enfermeiros gostariam de ser valorizados como profissionais e acreditam que terão 0 reconhecimento do seu trabalho. Tal sentimento tem aflorado nos enfermeiros, mesmo diante de situações adversas da prática de enfermagem. Eles querem contribuir com seus conhecimentos para ajudar o paciente a recuperar a qualidade de vida. Nesse aspecto, os enfermeiros caminham em direção aos seus objetivos, olhando constantemente para si mesmos e avaliando se estão aptos a alcançá-los.
Inter-relacionamento dos fenômenos e a descoberta da categoria central

Através da inter-relação dos dois fenômenos obtidos neste estudo, conforme Figura 3, procuramos integrar as categorias em termos de contexto, condições causais, estratégias e conseqüências, para descobrir a categoria central que reúnam todas as outras. Os fenômenos e seus respectivos componentes, de acordo com o modelo de paradigma de Strauss e Corbin ${ }^{(10)}$, foram reunidos e analisados teoricamente e interpretado a luz do interacionismo simbólico.

A categoria central que reúne as outras categorias é representada pelo processo: a busca da interação teoriaprática no sistema de informação em enfermagem. Esse processo apresenta duas dimensões: a formal ou explícita e a informal ou tácita. A dimensão explícita é caracterizada pela formalização do conhecimento em enfermagem e está diretamente relacionada às causas geradoras do fenômeno, aqui denominado de situação. A situação real, específica, é o contexto em que as ações e interações sociais ocorrem. A dimensão tácita representa o conhecimento capturado da prática, ou seja, a informação informal que permeia a prática clínica.

$\mathrm{Na}$ condição causal, os enfermeiros demonstraram interesse em conhecer os modelos formais e procuram articulá-los com a prática. Para isso, utilizam os diagnósticos de enfermagem da NANDA. No entanto, algumas barreiras têm dificultado essa prática e, assim, emerge a percepção de que existe uma lacuna entre a teoria e a prática.

Por outro lado, a sistematização é percebida pelos enfermeiros como um caminho para superar as lacunas e visualizar a resolução dos problemas da prática e do sistema de informação em enfermagem. Nesse contexto, a relação enfermeiro-paciente possibilita uma prática social humanizada e individualizada. Tudo isso constitui a vivência da prática de enfermagem.

Como estratégia, estão representadas as categorias que manifestam interesse de buscar alternativas que venham fortalecer a interação teoria-prática no sistema de informação em enfermagem, razão pela qual os enfermeiros procuram elementos da prática de enfermagem. Também são percebidas e avaliadas as restrições ao sistema de informação computadorizado que pode ser um instrumento de estímulo para superar as dificuldades de atuação na instituição. 
Em consonância com as estratégias fundamentadas nos elementos da prática, nas avaliações e na tentativa de minimizar as restrições ao sistema de informação computadorizado, os enfermeiros apontaram caminhos inter-relacionados, demonstrando que querem um sistema de informação que seja participativo em seu desenho, além de criativo, porque reconhecem as vantagens que o sistema traz para a prática de enfermagem.

Obviamente, as conseqüências advindas das estratégias assumidas e a integração dos fenômenos expostos levaram-nos a compreender que aquelas categorias indicavam a seguinte categoria central: a busca da interação teoria-prática no sistema de informação em enfermagem. Dessa maneira, todas as categorias foram integradas ao fenômeno central. Nesse processo de análise e integração, constatamos que os enfermeiros procuram, pela vivência prática, diminuir a lacuna entre teoria e prática, fazendo com que tenham aspirações com relação ao futuro profissional. O processo mostra que, apesar das limitações organizacionais e funcionais, os enfermeiros querem um sistema de informação que retrate a realidade da sua prática clínica (conhecimento tácito), mas que possa conter elementos do conhecimento formal (explícito), adequando-os a um sistema automatizado que contemple o processo de enfermagem na sua integralidade.

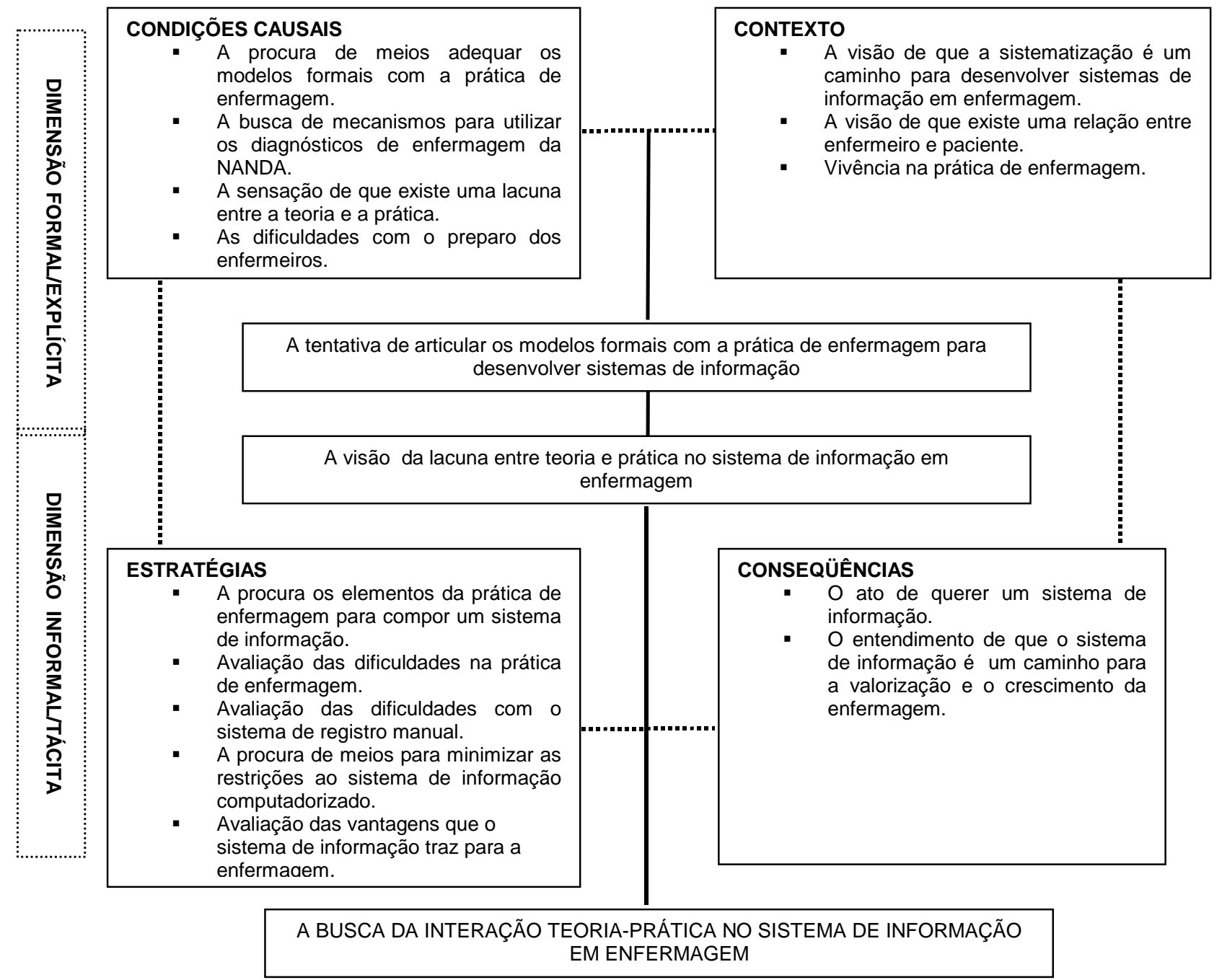

Figura 3 - A descoberta da categoria central: A busca da interação teoria-prática no sistema de informação em enfermagem

\section{CONCLUSÃO}

A categoria central: a busca da interação teoriaprática no sistema de informação em enfermagem indica que esta é uma decisão estritamente individual, tendo pouca ou nenhuma influência da organização. Os enfermeiros percebem que podem procurar um caminho, o qual, por meio do processo de sistematização, conduza- 
os a concretizar o desenvolvimento de um sistema de informação, que proporcione segurança e satisfação no exercício da prática de enfermagem.

Por outro lado, em nível social, esse processo mostra a vontade dos enfermeiros de crescer e sentir-se valorizados junto à sociedade, de modo que possam concretizar suas metas profissionais, tornando-as socialmente significativas. Nesse sentido, o desejo de crescer e ser valorizado estão integrados no processo a busca da interação teoria-prática no sistema de informação em enfermagem, porque tal interação permite tornar visível o conhecimento invisível que só existe em nível tácito e que está baseado na prática clínica. A interação teoriaprática significa, para os enfermeiros, a maneira pela qual eles podem tentar reduzir a lacuna entre a teoria e a prática no sistema de informação. Portanto, a categoria central encontrada é ação, conseqüência e processo. Ela significa um caminho a seguir em direção à valorização e ao crescimento da enfermagem.

\section{REFERÊNCIAS BIBLIOGRÁFICAS}

1. Santos SR, Paula AFA, Lima JP. O enfermeiro e sua percepção sobre o sistema manual de registro no prontuário. Rev Latino-am Enfermagem 2003 janeiro-fevereiro; 11(1):807.

2. Charon JM. Symbolic interactionism: an introduction, an interpretation, an integration. New Jersey (USA): Prentice Hall; 1989.

3. Luis MAV. Uma situação de trabalho conturbado ou enfermeiro: a identidade negada. [tese]. Ribeirão Preto (SP): Escola de Enfermagem de Ribeirão Preto/USP; 1991.

4. Blumer H. Symbolic interactionism: perspective e method. Berkely (USA): University of Califórnia; 1969.

5. Haguette TMF. Metodologias qualitativas na sociologia. Petrópolis (RJ): Vozes; 1990.

6. Mead GH. On social psychology. Chicago (USA): The University of Chicago Press; 1977.

7. Ângelo M. Vivendo uma prova de fogo: as experiências iniciais da aluna de enfermagem. [tese]. São Paulo (SP): Instituto de Psicologia/USP; 1989.

8. Ministério da Saúde (BR). Comissão Nacional de Ética em Pesquisa - CONEP. Resolução no 196/96. Dispõe sobre pesquisa envolvendo seres humanos. Brasília (DF): Ministério da Saúde; 1996.

9. Triviños ANS. Introdução à pesquisa em ciências sociais a pesquisa qualitativa em educação: o positivismo, a fenomenologia, o marxismo. São Paulo (SP): Atlas; 1994.

10. Strauss A, Corbin J. Basics of qualitative research: grounded theory - procedures and techniques. Newbury Park - California (USA): Sage Publication;1991.

11. Cassiani SHB. Buscando significado para o trabalho: o aperfeiçoamento profissional sob a perspectiva de enfermeiras. [tese]. São Paulo (SP): Escola de Enfermagem de Ribeirão Preto/USP; 1994.

12. Lippeveld T, Sauerbom R, Bodart C. Design and implementation of health information systems. Geneva: WHO; 2000.

13. Marin HF. Vocabulários em enfermagem: revisão e atualização. Nursing 2001 janeiro; 4(32):25-9.

14. Pan American Health Organization. Building standardbased nursing information systems. Washington (USA): PAHO; 2001.

15. Rolfe G. Closing the theory-practice gap. Oxford (UK): Butterworth-Heinemann; 1996. 